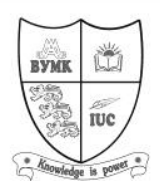

European Journal of Tourism Research

http://ejtr.vumk.eu

\title{
Duncan, T., Cohen, S. A. \& Thulemark, M. (eds) (2013). \\ Lifestyle mobilities. Ashgate. \\ ISBN: 978-1-4094-5371-0, 280 pp.
}

\author{
Reviewed by Svitlana larmolenko ${ }^{1}$
}

Received: 14/05/2014

\footnotetext{
${ }^{1}$ Recreation and Tourism, School of Human Ecology, Georgia Southern University, P.O. Box 8034 , GA 30458; tel: +1 252375 1971; email: siarmolenko@georgiasouthern.edu
}

(C) 2014 International University College. All rights reserved

Citation Duncan, T., Cohen, S. A. \& Thulemark, M. (eds) (2013). Lifestyle mobilities. Ashgate. ISBN: 978-1-4094-5371-0, 280 pp. Reviewed by Svitlana larmolenko, European Journal of Tourism Research 8, pp. 173-175

The recent emergence of transnational and mobility knowledge domains has spurred a whirlwind of research on mobile populations, their activities, identities, and meanings assigned to their mobile performance. While already working within this cutting edge mobilities network, authors in Lifestyle mobilities push the boundaries even further as they carve out a whole new type of mobility, which bridges between the temporary mobility of tourism and the more permanent one of migration (Chapter 1 ). It is in this in-between space that authors are able to discover and describe the fluid, identity forming, embodied, and almost nomadic way of existence that is lifestyle mobility.

Book editors were able to artfully bring together what initially seems like a wide variety of topics, approaches, and methods. The actual temporal and spatial everyday performance of mobility is exemplified through cases of a traveling art group (Chapter 2), exploration of the re-emerging movement of hitchhiking in Europe (Chapter 3), simultaneously detached and embedded wanderings of "dirt bags" (rock climbers; Chapter 4), and practice of imagined mobility to exotic places through advertisement of belly dancing holidays online (Chapter 5). A practical approach is exemplified by authors who upturn conventional research methods and create those better adapted to studying the fluid and fleeting world of mobile populations. Whether it involves allowing children to guide the researcher through their neighborhood in a "mobile research" minibus (Chapter 6), collecting rounds of email interviews with travelers over multiple years (Chapter 7), or entwining the mobility of self with that of others in a multi-sited ethnography (Chapter 8), these researchers urge us to apply methods that allow conducting mobile research 'with' those involved rather than 'on' them.

An important tension between mobilities and belonging is explored through how the routes are becoming more salient for a lifestyle traveler than his roots (Chapter 9), how lifestyle mobility becomes an expression of freedom from places for trans-Pacific blue 
water sailors (Chapter 10), how attachment to canoescapes creates a belonging that is deeply contextual (Chapter 11), and how cosmopolitanism and world citizenship allow individuals to move beyond ethnocentric localities to profess belonging to the global landscape (Chapter 12). Mobility as a building block of identity emerged as the binding matter of the next few chapters, albeit with different subthemes. While Chapter 13 looked at how mediascapes and imagined worlds exert effect on identities and through identities on desire for lifestyle mobility, the next three chapters focus on the significance of climate and weather in the formation of mobile lifestyles. The short term mobilities of storm watching in Vancouver Island (Chapter 14), the negotiations between different styles of mobility as related to sustainable travel choices (Chapter 15), and environmental challenges posed by mobility choices like rally racing (Chapter 16) all point to the difficult choice between increased mobility and sustainability that humanity will have to face in the future.

As the book builds a bridge between migration and tourism through introducing the lens of lifestyle mobilities, its theoretical contributions can be evaluated from the standpoint of these two fields: tourism and migration.

The paradigm of lifestyle mobilities has considerable consequences for the tourism domain, as engagement with the wider field of mobilities is seen as a crucial route for the development of tourism theory (Franklin and Crang 2001). Many tourism theorists engaged with the notion of discovering the self through tourism, while the lens of lifestyle mobilities allows extending that notion and exploring how the traveler is creating the self through the sensual, corporeal performance of mobility. Lifestyle mobility also provides a more suitable definition for designating, and a lens for studying, those groups and communities for whom 'niche market' is too simplistic of a label, as in case of blue water sailors. The cross fertilization of tourist, traveler, and world citizen that the book presents opens new horizons for studying of 174 relationship between the geographical and the social. For as authors suggest, the nature of mobility is profoundly social - a point that is largely ignored in the tourism literature focused on the inner workings, behaviors, and ideas of individual tourists. But probably the most important impact that mobilities have on tourism is serving as a constant reminder that tourism and travel are not limited to the exotic places, but is perpetual and embedded in the everyday practices and needs to be looked at as such.

On the other hand, the implications of lifestyle mobilities paradigm for the migration literature are tremendous, as multiple limitations within migration studies are challenged by the notion of mobilities. First, migration studies focus on the movement of people across borders, while largely ignoring other mobilities - those of capital, information, knowledge, and skills. The wider lens of mobility allows for incorporating those other kinds of mobilities and including them in the wider contextual study of movement. Second, migration mainly focuses on the movement between places, while authors working with the lifestyle mobilities lens are just as concerned with the mobility within a place, and its implications for the everyday embodied performance of movement. The meanings individuals assign to movement within a place can prove just as transformative as migration to a faraway location. Third, the study of migrant acculturation upon relocating is mainly based on the binary of incorporation/rejection, judging the success of migrant adaptation on how well migrants are able to incorporate into the host society. Mobilities paradigm challenges the incorporation/rejection binary by providing individuals with an array of idiosyncratic options, dictated by personal motivations as well as contextual factors. Moreover, individuals adopting a cosmopolitan mobile lifestyle can break out of attachment to place altogether, becoming a new class of world citizens.

I believe this book will be of exceptional value in the academic environment. Chapters and case studies from the book could be easily incorporated into syllabi of graduate courses 
in tourism, anthropology, sociology, and migration programs. The section on mobile research methods is likely to inspire scholars to adopt more in-depth research 'with' the subjects by providing guidelines on conducting multi-sited ethnographies, mobile transport research, or longitudinal studies through emails. On the other hand, the sometimes challenging language of the book is likely to prevent the book from being used in undergraduate level courses, as well as by industry practitioners. If that is ever to become a goal, an instructors' manual or executive summary might be considered by the editors. Also, future editions might consider including works that focus on the mobilities of those with lesser means, as now generally research is conducted on those who are privileged enough to undertake recurrent or continuous travel.
Overall, I would enthusiastically recommend this book to all those seeking to further their understanding of all facets of movement, whether it's human or otherwise, between or within places, corporeal or imagined. The variety of chapters and topics offered, and the novelty of the lifestyle mobility lens, is sure to spur numerous discussions and follow-up works on the topic.

\section{References}

Franklin, A., \& Crang, M.. (2001). The trouble with tourism and travel theory. Tourist studies, 1(1), 5-22. 